\title{
Bronchoesophageal fistula
}

\author{
David W. Barbara, MD · Stephen M. Broski, MD $\cdot$ Shanda Blackmon, MD, MPH
}

Received: 11 July 2017/Revised: 13 July 2017/Accepted: 31 July 2017/Published online: 7 August 2017

(C) Canadian Anesthesiologists' Society 2017

A 57-yr-old woman with a history of radiation to the neck and mediastinum for Hodgkin's lymphoma years prior presented with coughing during eating, dysphagia, and unintentional weight loss. Her investigation revealed a bronchoesophageal fistula (Figure), and she was referred for surgery. Airway management with preservation of spontaneous ventilation and flexible bronchoscopic (FB) intubation was considered to avoid positive-pressure ventilation and iatrogenic injury during intubation to the area involving the fistula. However, given a reassuring upper airway examination and potential difficulty associated with awake intubation with a double-lumen endotracheal tube (DL-ETT), the decision was made to proceed otherwise. Following induction of general anesthesia and administration of succinylcholine, the trachea was intubated via direct laryngoscopy followed immediately by further FB-guided advancement of the leftsided DL-ETT into the appropriate position. Positivepressure ventilation was thus avoided in the right lung entirely. Following successful repair of the fistula, expeditious extubation was performed to avoid positivepressure ventilation of the surgically repaired bronchus.
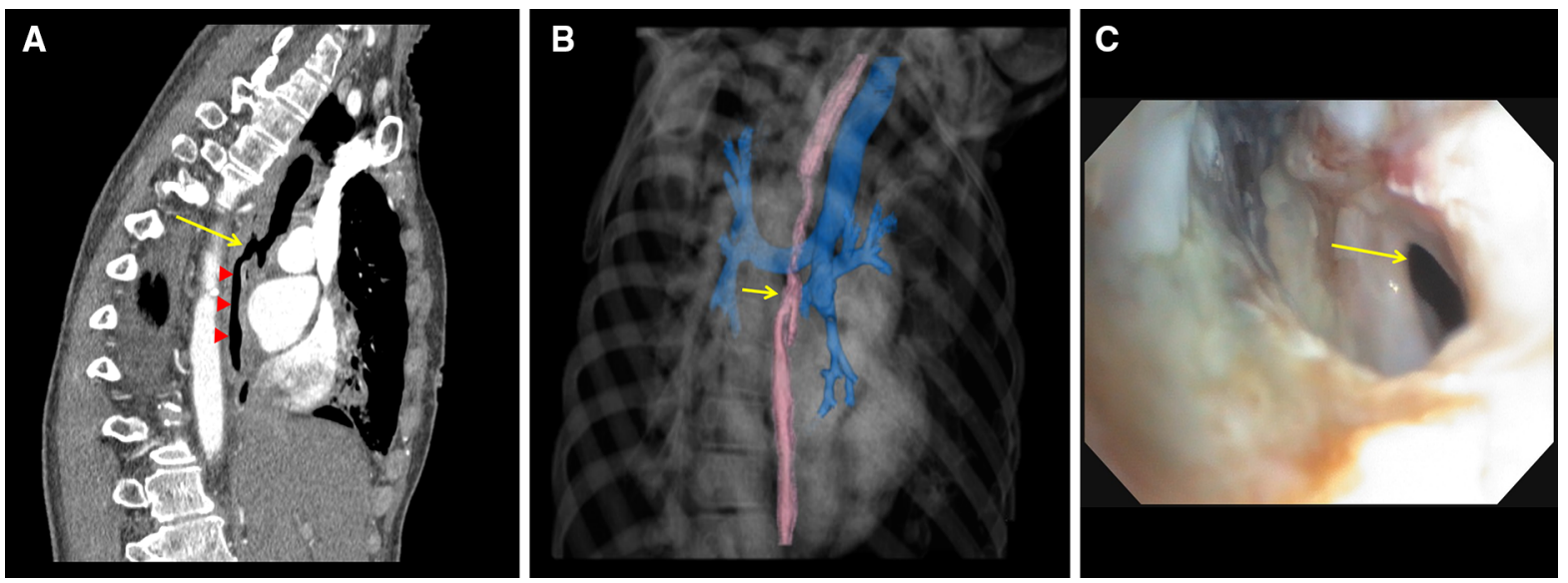

Figure A) Oblique sagittal contrast-enhanced computed tomography (CT) scan of the chest shows a fistulous connection (yellow arrow) between the posterior right main stem bronchus and the mid-thoracic esophagus. The esophagus distal to the fistula is air-filled (red arrowheads). B) Three-dimensional reformatted CT reconstruction from a right posterior oblique view shows the esophagus (pink) and bronchial tree (blue). The fistula is again seen (yellow arrow) between the posterior right main stem bronchus and the esophagus. C) Flexible bronchoscopic view with the fistula easily seen (yellow arrow) between the right main stem bronchus and the (dark) esophagus

D. W. Barbara, MD $(\bowtie) \cdot$ S. M. Broski, MD .

S. Blackmon, MD, MPH

Mayo Clinic College of Medicine, Rochester, MN, USA

e-mail: Barbara.David@mayo.edu 
Bronchoesophageal fistulas, which are less common than tracheoesophageal fistulas, may form congenitally or be acquired later in life. ${ }^{1,2}$ Although more prevalent in pediatric patients, adults may present with congenital or acquired bronchoesophageal fistulas that occur spontaneously or secondary to malignancy, irradiation, trauma, caustic ingestion, foreign bodies, or infection. Symptoms include cough with oral intake, dysphagia, aspiration, recurrent respiratory infections, and gastric distention. It can be diagnosed using bronchoscopy, gastrointestinal endoscopy, or radiologic imaging. Definitive treatment is surgical in most cases. Anesthetic considerations during surgical repair include potential difficulties with oxygenation and/or positive-pressure ventilation (with possible gastric insufflation), risk of pulmonary contamination with gastric contents via the fistula, and further iatrogenic enlargement of the fistula. ${ }^{1}$
Disclosures None.

Conflicts of interest None declared.

Editorial responsibility This submission was handled by Dr. Hilary P. Grocott, Editor-in-Chief, Canadian Journal of Anesthesia.

Financial support Support was provided solely from institutional and/or departmental sources.

\section{References}

1. Robins B, Das AK. Anesthetic management of acquired tracheoesophageal fistula: a brief report. Anesth Analg 2001; 93 : 903-5.

2. Zhang BS, Zhou NK, Yu CH. Congenital bronchoesophageal fistula in adults. World J Gastroenterol 2011; 17: 1358-61. 